\title{
PENILAIAN KUALITAS DATA RUTIN DI PUSKESMAS KARANG REJO KOTA TARAKAN MENGGUNAKAN ROUTINE DATA QUALITY ASSESMENT
}

\author{
Haikal $^{1 *}$, Martini ${ }^{2}$, Eko Sediyono ${ }^{3}$ \\ ${ }^{1}$ Staf Pengajar Fakultas Kesehatan Universitas Dian Nuswantoro \\ ${ }^{2}$ Staf Pengajar Program Magister Ilmu Kesehatan Masyarakat Universitas Diponegoro \\ ${ }^{3}$ Staf Pengajar Program Magister Sistem Informasi Universitas Kristen Satya Wacana \\ *Email: haikalfaqih@dsn.dinus.ac.id
}

\begin{abstract}
Pusat Data dan Informasi Kementerian Kesehatan Indonesia melaporkan bahwa kualitas data kesehatan di Indonesia masih rendah. Data yang diolah kemudian menjadi informasi berperan penting untuk pengambilan keputusan. Penggunaan data yang buruk akan berdampak pada keputusan yang diambil oleh para pemimpin. Penelitian ini bertujuan untuk menilai kualitas data rutin pada surveilans Epidemiologi Demam Berdarah Dengue di Puskesmas Karang Rejo Kota Tarakan. Metode penelitian menggunakan penelitian operasional. Data dikumpulkan menggunakan data sekunder. Data sekunder terdiri dari laporan data rutin Epidemiologi Demam Berdarah Dengue pada 2016-2018. Laporan data rutin akan diproses dan dianalisis menggunakan metode Penilaian Kualitas Data Rutin (RDQA). Hasil penelitian menunjukkan kemampuan pemantauan dan evaluasi adalah 86\%, Indikator dan Pedoman Pelaporan adalah 100\%, Pengumpulan Data dan Formulir Koleksi adalah 100\%, Proses Manajemen Data adalah 60\% dan Penggunaan Data untuk Pengambilan Keputusan adalah 100\%.

Keyword: Surveilans Epidemiologi DBD, Pengukuran Kualitas Data Rutin, Pusat Kesehatan Masyarakat

ABSTRAK

Indonesian Ministry of Health Data and Information Center reports that the quality of health data in Indonesia is still low. The data that is processed then becomes information plays an important role for decision making. The use of bad data will have an impact on decisions taken by leaders. This study aims to assess the quality of routine data on Dengue Hemorrhagic Fever Epidemiology surveillance at the Karang Rejo Health Center in Tarakan City. The research method uses operational research. Data is collected using secondary data. Secondary data consists of routine data reports of Dengue Hemorrhagic Fever Epidemiology in 2016-2018. Routine data reports will be processed and analyzed using the Routine Data Quality Assessment (RDQA) method. The results showed the ability of monitoring and evaluation was 86\%, Indicators and Reporting Guidelines were 100\%, Data Collection and Collection Forms were $100 \%$, Data Management Process was $60 \%$ and Data Use for Decision Making was $100 \%$. Kata kunci: Surveillance Epidemiology DHF, Routine Data Quality Assesment, Public Health Center
\end{abstract}




\section{PENDAHULUAN}

Berdasarkan laporan Pusat Data Kesehatan Kementerian Kesehatan Republik Indonesia, ditemukan bahwa kualitas data di Indonesia masih rendah. Penilaian terhadap SIK pada tahun 2012 menunjukkan bahwa hasil untuk indikator (62\%), sumber daya (60\%), kualitas data (57\%), sumber data $(51 \%)$, manajemen data (42\%), penggunaan dan diseminasi data (62\%). Padahal, SIK merupakan bagian terpenting dalam penyediaan informasi untuk proses pengambilan keputusan. (Kementrian Kesehatan Republik Indonesia, 2013)

Kepala Seksi Surveilans DKK Tarakan mengungkapkan bahwa terdapat beberapa permasalahan yang berhubungan dengan kualitas data. Pada tahun 2018, Puskesmas Karang Rejo mengirimkan laporannya diatas tanggal 5 (terlambat). Ketidaksesuaian antara jumlah data sumber dan hasil rekapitulasi yaitu jumlah kasus DBD di Puskesmas Karang Rejo dengan jumlah kasus DBD di Dinas Kesehatan Kota Tarakan, kemudian ditemukannya ketidaksesuaian antara format pelaporan dan pencatatan oleh gasurkes.

RDQA merupakan tools yang diperkenalkan WHO sebagai hasil kerjasama dengan the Measure Evaluation project, Program for AIDS Relief (PEPFAR), The Global Fund dan President's Emergency. RDQA adalah tools yang digunakan untuk penilaian kualitas data berdasarkan waktu tertentu melalui penilaian sistem penghasil data, verifikasi data dan rencana peningkatan kualitas data. Peningkatan kualitas data dapat dilakukan dengan menggunakan pendekatan pada
Routine Data Quality Assesment (RDQA). (Evaluation, 2015)

Penilaian terhadap kualitas data yang tepat akan mampu mengatasi permasalahan terkait kualitas data yang buruk. Penilaian yang tepat akan mampu untuk menghasilkan gambaran terkait kelemahan-kelemahan yang ada pada surveilans epidemiologi DBD di Puskesmas Karang Rejo, sehingga akan dapat dilakukan cara untuk meningkatkan kualitas data yang ada.

Penelitian ini bertujuan untuk melakukan penilaian kualitas data rutin surveilans epidemiologi DBD di Puskesmas Karang Rejo Kota Tarakan menggunakan Routine Data Quality Assesment (RDQA).

\section{METODE}

Penelitian menggunakan jenis penelitian Operational Research (OR). Operational Research (OR) atau Penelitian operasional merupakan penelitian yang memberikan solusi terkait masalah operasional pelaksanaan program / kegiatan yang hasilnya digunakan untuk membantu mengatasi permasalahan. OR didasarkan pada masalah yang ditemukan dilapangan yang memerlukan penelitian untuk pemecahannya. (Budi, Artha. Djannatun, Titiek. Syamsul, 2012)

Data yang dikumpulkan ialah data sekunder. Data sekunder menggunakan data rutin pada surveilans epidemiologi DBD tahun 2016-2018. Data sekunder akan diolah dan dianalisis menggunakan metode RDQA. Penelitian dilakukan di Puskesmas Karang Rejo Kota Tarakan. Data yang ada kemudian menjadi bahan analisis RDQA dan ditampilkan dalam tabel. 
Dokumen yang dilakukan analisis yaitu Laporan K-DBD Puskesmas, Laporan K-DBD Dinas Kesehatan Kota, Laporan KD-RS Puskesmas, Laporan W2-DBD Puskesmas, Laporan W2-DBD Dinas Kesehatan Kota dan Laporan Juru Pemantau Jentik. Analisis menggunakan penilaian pada RDQA yaitu Verifikasi Data, Penilaian Sistem yang menghasilkan Data dan Rencana Peningkatan Kualitas Data.

\section{HASIL}

Sebelum menggunakan metode RDQA, data yang harus dipersiapkan yaitu: Laporan K-DBD Puskesmas, Laporan KDBD Dinas Kesehatan Kota, Laporan KDRS Puskesmas, Laporan W2-DBD Puskesmas, Laporan W2-DBD Dinas Kesehatan Kota dan Laporan Juru Pemantau Jentik

Data yang dipersiapkan kemudian dilakukan entri pada aplikasi RDQA untuk telaah laporan atau penilaian kualitas data. Indikator penilaian kualitas data menggunakan RDQA yaitu: Verifikasi Data, Penilaian Sistem yang menghasilkan Data dan Rencana Peningkatan Kualitas Data.

Data yang selesai diinputkan pada aplikasi metode RDQA diolah secara otomatis. Output dari aplikasi RDQA merupakan informasi mengenai ketiga indikator kualitas data menurut RDQA, yaitu:

\section{Verifikasi Data}

a. Review Dokumen

Pada review dokumen, melakukan penilaian terhadap ketersediaan dan kelengkapan dari semua indikator dokumendokumen sumber selama periode laporan yang akan dinilai.
Tabel 1. Review Dokumen

\begin{tabular}{llccc}
\hline \multirow{2}{*}{ Pertanyaan } & \multicolumn{3}{c}{ Indikator } \\
\cline { 2 - 5 } & $\mathrm{IR}$ & $\mathrm{CFR}$ & $\mathrm{ABJ}$ \\
\hline $\begin{array}{l}\text { Apakah semua data sumber } \\
\text { tersedia untuk dilakukan } \\
\text { review? }\end{array}$ & $\mathrm{Y}$ & $\mathrm{Y}$ & $\mathrm{Y}$ \\
\hline $\begin{array}{l}\text { Apakah data yang tersedia } \\
\text { telah lengkap? }\end{array}$ & $\mathrm{Y}$ & $\mathrm{Y}$ & $\mathrm{Y}$ \\
\hline $\begin{array}{l}\text { Apakah data sumber telah } \\
\text { dilaporkan tepat waktu? }\end{array}$ & $\mathrm{Y}$ & $\mathrm{Y}$ & $\mathrm{Y}$ \\
\hline
\end{tabular}

b. Laporan Hasil Penghitungan Ulang

Pada laporan hasil penghitungan ulang, melakukan pengecekan terhadap dokumen sumber melalui dokumen rekapitulasi yang tersedia kemudian memberikan penjelasan apabila terdapat perbedaan hasil.

Tabel 2. Laporan Hasil Penghitungan

\begin{tabular}{|c|c|c|c|}
\hline \multirow{2}{*}{ Pertanyaan } & \multicolumn{3}{|c|}{ Indikator } \\
\hline & IR & CFR & $\mathrm{ABJ}$ \\
\hline $\begin{array}{l}\text { Apakah Data yang ada pada } \\
\text { Dokumen Sumber telah sesuai } \\
\text { dengan Laporan Rekapitulasi }\end{array}$ & $\mathrm{Y}$ & $\mathrm{Y}$ & $\mathrm{Y}$ \\
\hline
\end{tabular}

\section{c. Cross-check Hasil Pelaporan}

Pada cross-check hasil pelaporan, melakukan pengecekan terhadap hasil laporan dengan sumber-sumber data lain yang terkait.

Tabel 3. Cross-check Hasil Pelaporan

\begin{tabular}{lccc}
\hline \multirow{2}{*}{ Pertanyaan } & \multicolumn{3}{c}{ Indikator } \\
\cline { 2 - 4 } & IR & CFR & ABJ \\
\hline Apakah Data yang ada pada & $\mathrm{Y}$ & $\mathrm{Y}$ & $\mathrm{Y}$ \\
Dokumen Sumber telah sesuai & & & \\
dengan Data pada dokumen & & & \\
terkait lainnya & & & \\
\hline
\end{tabular}




\section{Penilaian Sistem}

a. Kemampuan Unit Monitoring dan Evaluasi

Penilaian terkait kemampuan unit monitoring dan evaluasi terdiri atas kemampuan petugas dalam melakukan pencatatan serta memeriksa pengumpulan data di puskesmas.

Tabel 4. Kemampuan Unit Monitoring dan Evaluasi

\begin{tabular}{|c|c|}
\hline Pertanyaan & Jawaban \\
\hline $\begin{array}{l}\text { Apakah petugas yang terlibat telah } \\
\text { mengikuti pelatihan manajemen data? }\end{array}$ & $Y$ \\
\hline $\begin{array}{l}\text { Apakah terdapat petugas yang } \\
\text { bertanggung jawab dalam pencatatan } \\
\text { dokumen? }\end{array}$ & $\mathrm{Y}$ \\
\hline $\begin{array}{l}\text { Apakah terdapat petugas yang } \\
\text { bertanggungjawab untuk meninjau } \\
\text { laporan rutin sebelum diserahkan ke } \\
\text { DKK? }\end{array}$ & $Y$ \\
\hline $\begin{array}{l}\text { Apabila petugas yang bertanggungjawab } \\
\text { tidak hadir, apakah terdapat petugas lain } \\
\text { yang menggantikan? }\end{array}$ & $Y$ \\
\hline $\begin{array}{l}\text { Apakah puskesmas menerima umpan- } \\
\text { balik dari DKK terkait laporan yang } \\
\text { telah diberikan? }\end{array}$ & $\mathrm{Y}$ \\
\hline $\begin{array}{l}\text { Apakah DKK pernah melakukan } \\
\text { pertemuan atau supervisi kepada } \\
\text { Puskesmas? }\end{array}$ & $\mathrm{Y}$ \\
\hline $\begin{array}{l}\text { Apakah dalam } 3 \text { bulan terakhir telah } \\
\text { dilakukan pertemuan atau supervisi oleh } \\
\text { DKK? }\end{array}$ & $\mathrm{T}$ \\
\hline
\end{tabular}

\section{b. Indikator dan Pedoman Pelaporan}

Penilaian terkait Indikator dan Pedoman Pelaporan merupakan penilaian terkait ketersediaan pedoman tertulis pada puskesmas.

Tabel 5. Indikator dan Pedoman Pelaporan

\begin{tabular}{lc}
\hline \multicolumn{1}{c}{ Pertanyaan } & Jawaban \\
\hline Apakah Puskesmas memiliki salinan & $\mathrm{Y}$ \\
petunjuk tertulis terkait indikator & \\
DBD? & \\
\hline
\end{tabular}

\begin{tabular}{ll}
\hline Apakah puskesmas memiliki salinan & $\mathrm{Y}$ \\
petunjuk tertulis terkait teknis & \\
pencatatan dan pelaporan dari & \\
masing-masing indikator? & \\
\hline $\begin{array}{l}\text { Apakah puskesmas memiliki salinan } \\
\text { petunjuk tertulis terkait persyaratan }\end{array}$ & \\
perlaporan dan tenggat waktu ? & \\
\hline Apakah petunjuk tertulis yang & $\mathrm{Y}$ \\
diberikan DKK cukup untuk & \\
memastikan pencatatan dan & \\
pelaporan telah terstandar? & \\
\hline
\end{tabular}

c. Pengumpulan Data dan Ketersediaan Formulir

Pengumpulan Data dan Ketersediaan Formulir merupakan penilaian terhadap pengumpulan data yang memiliki standar, bentuk pelaporan yang sistematis dan pencatatan data yang detail untuk mengukur indikator data yang dibutuhkan.

Tabel 6. Pengumpulan Data dan Ketersediaan Formulir

\begin{tabular}{ll}
\hline \multicolumn{3}{c}{ Pertanyaan } & Jawaban \\
\hline $\begin{array}{l}\text { Apakah program nasional telah } \\
\text { memberikan formulir pelaporan } \\
\text { terstandar? }\end{array}$ & \\
\hline $\begin{array}{l}\text { Apakah formulir pelaporan terstandar } \\
\text { telah konsisten digunakan di } \\
\text { puskesmas? }\end{array}$ & \\
\hline $\begin{array}{l}\text { Apakah keseluruhan puskesmas } \\
\text { menggunakan formulir pelaporan }\end{array}$ & $\mathrm{Y}$ \\
terstandar yang sama? & \\
\hline $\begin{array}{l}\text { Apakah puskesmas memiliki salinan } \\
\text { petunjuk untuk melengkapi formulir } \\
\text { pelaporan dan pengumpulan data? }\end{array}$ & $\mathrm{Y}$ \\
\hline $\begin{array}{l}\text { Apakah puskesmas memiliki cadangan } \\
\text { formulir pelaporan untuk menghindari } \\
\text { kehabisan form? }\end{array}$ & $\mathrm{Y}$ \\
\hline
\end{tabular}

\section{d. Proses Manajemen Data}

Penilaian terkait proses manajemen data merupakan penilaian terhadap pengelolaan data yang dimulai dari pengumpulan data, proses atau pengolahan 
data, pembuatan informasi, serta penyajian data atau informasi pada surveilans epidemiologi DBD.

\section{Tabel 7. Proses Manajemen Data}

\begin{tabular}{lc}
\hline \multicolumn{1}{c}{ Pertanyaan } & Jawaban \\
\hline $\begin{array}{l}\text { Apakah terdapat pemeriksaan kualitas } \\
\text { data pada saat memindahkan laporan }\end{array}$ & $\mathrm{T}$ \\
dari kertas ke komputer? & \\
\hline $\begin{array}{l}\text { Apakah pemeriksaan kualitas data } \\
\text { dilakukan pada laporan bulanan }\end{array}$ & \\
puskesmas? & \\
\hline $\begin{array}{l}\text { Apakah puskesmas melakukan back-up } \\
\text { data? }\end{array}$ & $\mathrm{Y}$ \\
\hline $\begin{array}{l}\text { Apakah bakcup data rutin dilakukan? } \\
\text { (mingguan atau bulanan) }\end{array}$ & $\mathrm{Y}$ \\
\hline $\begin{array}{l}\text { Apakah pada pencatatan dan pelaporan } \\
\text { dapat mencegah adanya data ganda? }\end{array}$ & $\mathrm{T}$ \\
\hline
\end{tabular}

e. Penggunaan Data untuk Pengambilan Keputusan

Penilaian terkait penggunaan data untuk pengambilan keputusan merupakan penilaian terhadap kemampuan laporan untuk menghasilkan data yang berguna untuk pengambilan keputusan.

Tabel 8. Penggunaan Data untuk Pengambilan Keputusan

\begin{tabular}{|c|c|}
\hline Pertanyaan & Jawaban \\
\hline $\begin{array}{l}\text { Apakah puskesmas mengembangkan } \\
\text { grafik, diagram, peta, dll untuk } \\
\text { penyampaian data? }\end{array}$ & $\mathrm{Y}$ \\
\hline $\begin{array}{l}\text { Apakah tersedia petugas yang rutin } \\
\text { untuk mengembangkan grafik, } \\
\text { diagram, peta, dll untuk penyampaian } \\
\text { data? }\end{array}$ & $Y$ \\
\hline $\begin{array}{l}\text { Apakah tersedia petugas yang } \\
\text { menginterpretasikan dan menganalisis } \\
\text { data atau hasil pelaporan? }\end{array}$ & $\mathrm{Y}$ \\
\hline $\begin{array}{l}\text { Apakah petugas yang terlibat memiliki } \\
\text { pedoman atau petunjuk teknis terhadap } \\
\text { penggunaan data ? (mis. melalui } \\
\text { pertemuan dengan } \text { dkk terkait } \\
\text { penggunaan data) }\end{array}$ & $Y$ \\
\hline
\end{tabular}

\begin{tabular}{|c|c|}
\hline $\begin{array}{l}\text { Apakah hasil olahan data disampaikan } \\
\text { pada stakeholder terkait ? (mis. } \\
\text { Kelurahan, komunitas lainnya) }\end{array}$ & $\mathrm{Y}$ \\
\hline $\begin{array}{l}\text { Apakah terdapat program yang telah } \\
\text { dijalankan berdasarkan hasil dari } \\
\text { olahan data? }\end{array}$ & $\mathrm{Y}$ \\
\hline
\end{tabular}

\section{Rencana Peningkatan Kualitas Data}

Pada bagian ini, dilakukan review terhadap hasil dari penilaian sistem di Puskesmas Karang Rejo. Review tersebut terdiri atas kelemahan-kelemahan pada kualitas data yang teridentifikasi serta kegiatan yang akan dilakukan untuk mengatasi kelemahan tersebut.

Tabel 9. Rencana Peningkatan Kualitas Data

\begin{tabular}{|c|c|c|}
\hline Kelemahan & Tindakan & $\begin{array}{c}\text { Penanggung } \\
\text { Jawab }\end{array}$ \\
\hline $\begin{array}{l}\text { Tidak } \\
\text { melakukan } \\
\text { post-entry } \\
\text { verifikasi pada } \\
\text { data laporan }\end{array}$ & $\begin{array}{l}\text { melakukan } \\
\text { post-entry } \\
\text { verifikasi pada } \\
\text { data laporan }\end{array}$ & $\begin{array}{l}\text { Petugas } \\
\text { Pengelola } \\
\text { Data } \\
\text { Puskesmas }\end{array}$ \\
\hline $\begin{array}{l}\text { Supervisi } \\
\text { hanya } \\
\text { dilakukan } \quad 6 \\
\text { bulan sekali }\end{array}$ & $\begin{array}{l}\text { Pelaksanaan } \\
\text { Supervisi oleh } \\
\text { Dinas } \\
\text { dilakukan } 3 \\
\text { bulan sekali }\end{array}$ & $\begin{array}{l}\text { Ketua } \\
\text { Program } \\
\text { DBD DKK }\end{array}$ \\
\hline
\end{tabular}

\section{PEMBAHASAN}

Pada penilaian verifikasi data, presentase untuk review dokumen sebesar $100 \%$. Sumber Data telah tersedia, lengkap dan tepat waktu. Sumber Data telah lengkap yaitu keadaan dimana semua data yang tersedia pada unit telah lengkap. Sedangkan ketepatan waktu merupakan lamanya waktu antara ketersediaan data dan peristiwa atau fenomena itu terjadi, ketepatan waktu mengacu pada jeda waktu antara tanggal rilis data dan target ketika seharusnya telah disampaikan yaitu setiap tanggal 5 setiap 
bulannya. (Who, Norval and Sebert, 2010) Ketersediaan Data pada Surveilans Epidemiologi DBD merupakan keadaan laporan yang harus tersedia pada unit kesehatan yaitu Dinas Kesehatan Kota dan Puskesmas. (Kemenkes, 2010)

Pada aspek penilaian sistem, presentase untuk kemampuan unit monitoring dan evaluasi sebesar $85 \%$. Indikator yang belum sesuai yaitu supervisi tidak dilakukan oleh dinas kesehatan kota selama 3 bulan terakhir. Supervisi merupakan melihat atau meninjau yang dilakukan oleh atasan terhadap pelaksanaan kegiatan bawahannya sehingga, peran supervisi sangat penting dalam sebuah organisasi. (Suharsimi, 2006)

Indikator dan Pedoman Pelaporan telah berada pada nilai ideal yaitu $100 \%$. Tersedianya definisi operasional, formulasi perhitungan dan sumber data untuk data yang dikumpulkan, Tersedianya pedoman pengumpulan data, pengolahan data, validasi dan pembuatan laporan pada Puskesmas Karang Rejo telah memenuhi semua aspek pada Indikator dan Pedoman Pelaporan. (Boone, David; Tran Ba Huy, Ronald; Pervilhac, Cyril; La Tour, 2008)

Pengumpulan Data dan Ketersediaan Formulir telah berada pada nilai ideal yaitu $100 \%$. Terdapat petunjuk tertulis terkait program untuk memastikan pencatatan dan pelaporan data telah memiliki standar, Fasilitas kesehatan dan dinas kesehatan memiliki salinan petunjuk yang jelas tentang bagaimana pengumpulan data yang lengkap, Sumber dokumen dan format pelaporan yang relevan telah tersedia untuk kebutuhan audit, Memiliki cukup formulir pengumpulan dan pelaporan data yang kosong sebagai cadangan untuk menghindari kekurangan formulir. (Boone, David; Tran Ba Huy, Ronald; Pervilhac, Cyril; La Tour, 2008)

Proses Manajemen Data memiliki presentase $60 \%$. Indikator yang belum sesuai yaitu pemeriksaan kualitas data saat pemindahan dari kertas menuju komputer dan pencegahan terhadap data ganda. Pemeriksaan kualitas data secara berkala merupakan bagian penting dari praktek manajemen yang baik dan karena itu merupakan bagian yang integral dari kebutuhan manajemen sehari-hari. (ProsserSnelling and Morris, 2017) Permasalahan data ganda disebabkan oleh kesalahan sistem atau kesalahan pengguna dalam memasukkan data pada sistem atau perhitungan yang salah. (Tziovara, Vassiliadis and Simitsis, 2007)

$$
\text { Pengunaan Data untuk }
$$

Pengambilan Keputusan memiliki presentase yang ideal yaitu $100 \%$. Telah terdapat petugas di Puskesmas Karang Rejo yang mengembangkan grafik, diagram dan peta serta menginterpretasikan dan menganalisis data hasil pelaporan. Petugas Puskesmas Karang Rejo juga memiliki pedoman terhadap penggunaan data, disampaikan kepada kelurahan serta menjalankan program berdasarkan hasil dari olahan data yaitu melakukan fogging focus. Ketersediaan informasi kesehatan rutin sangat penting untuk perencanaan dan pengambilan keputusan. (Stewart, 2014)

\section{SIMPULAN}

1. Kualitas data pada Puskesmas Karang Rejo yaitu menunjukkan kemampuan unit monitoring dan evaluasi adalah 
$86 \%$, Indikator dan Pedoman Pelaporan adalah $100 \%$, Pengumpulan Data dan Ketersediaan Formulir adalah $100 \%$, Proses Manajemen Data adalah 60\% dan Penggunaan Data untuk Pengambilan Keputusan adalah 100\%.

2. Rencana peningkatan kualitas data yang dapat dilakukan oleh Puskesmas Karang Rejo adalah melakukan post-entry verifikasi pada data laporan dan pelaksanaan supervisi oleh dinas dilakukan 3 bulan sekali

\section{DAFTAR PUSTAKA}

Boone, David; Tran Ba Huy, Ronald; Pervilhac, Cyril; La Tour, A. (2008) 'Routine Data Quality Assessment Tool ( Rdqa )', pp. 1-17.

Budi, Artha. Djannatun, Titiek. Syamsul, R. (2012) Panduan Penelitian Operasional Tahun 2012. Jakarta. Available at: https://www.yarsi.ac.id/tbcare/pedoman-penelitianoperasionaloperational-research/.

Evaluation, M. (2015) 'User Manual Routine Data Quality Assessment', (October).

Kemenkes (2010) 'Demam Berdarah Dengue', Buletin Jendela Epidemiologi, 2, p. 48.

Kementrian Kesehatan Republik Indonesia (2013) 'Penilaian Mandiri Kualitas Data Rutin ( PMKDR ) Sistem Informasi Kesehatan'.

Prosser-Snelling, E. and Morris, E. (2017) 'Quality Indicators', Obstetrics, Gynaecology and Reproductive Medicine, 27(9), pp. 290-292. doi: 10.1016/j.ogrm.2017.06.008.
Stewart, S. (2014) 'IMPROVING DATA FOR DECISION-MAKING : LEVERAGING DATA QUALITY AUDITS IN HARYANA, INDIA', (May).

Suharsimi, A. (2006) Dasar-Dasar Supervisi. PT Rineka Cipta.

Tziovara, V., Vassiliadis, P. and Simitsis, A. (2007) 'Deciding the physical implementation of ETL workflows', DOLAP: Proceedings of the ACM International Workshop on Data Warehousing and OLAP, pp. 49-56. doi: 10.1145/1317331.1317341.

Who, Norval, P.-Y. and Sebert, J. (2010) 'Manual on use of Routine Data Quality Audit ( RDQA ) tool for TB monitoring', Who, (March), pp. 1-36. Available at: http://whqlibdoc.who.int/publication s/2011/9789241501248_eng.pdf. 